\title{
Preface
}

\section{WHY THIS BOOK WITH THESE AUTHORS}

This book is the result of a shared interest in effective design leadership and how to master it within complex and ever-changing organizations. During the course of their academic careers, Gerda and Giulia have completed numerous studies on design management, done research with industry partners, published extensively on design management, and lectured at leading design and business schools. Eric, on the other hand, has a longstanding and successful professional design career that includes several executive design leadership roles in companies renowned for their design and innovation track record, including Royal Philips and 3M Company. His achievements have been cited and featured in a number of books and international publications, and Eric is a frequent guest lecturer and keynote speaker on design leadership, brand, and innovation.

In hindsight, it makes perfect sense for these three authors to collaborate on the subject matter in this book. Gerda and Giulia had originally intended to write an academic paper on effective design leadership, and to this end, they interviewed many practitioners who occupied senior design leadership roles at the time. As part of this research, they also asked Eric about the practices, methods, and approaches he considered essential for effective design leadership. The transcript of Eric's replies revealed that there was so much more he could share about design leadership and that the one interview with him had only scratched the surface. During one of the conversations that followed, Eric mentioned that he had been wondering for a while when the opportunity would arise for him to capture his experiences in a book on design leadership. This made Gerda and Giulia ask 
themselves whether they should pivot and write a book together with Eric instead. A book - particularly one published by a reputable publisher like Stanford University Press - could potentially reach a much wider audience than an academic article. Gerda and Giulia had gained some interesting insights during interviews they had conducted with several senior design leaders for their academic research. But these interviews were usually one-time, one-hour sessions; the idea of being able to write a book with Eric, and tap into his knowledge and experience in an unlimited way, was extremely appealing. The possibility of working with Gerda and Giulia was equally attractive to Eric, as it offered an opportunity to enrich his perspectives and reflect on his professional experience from a more academic point of view. On the basis of these considerations, the three authors decided to join forces and embark on the journey of writing a book on design leadership together.

Design Leadership Ignited is the fruit of the combined efforts of its authors. It provides practical guidance to (aspiring) design leaders grounded on the authors' combined expertise and ongoing exchanges, the content and analysis of Gerda's and Giulia's interviews with senior design leaders, a deep dive into relevant professional and academic publications, and Eric's extensive and practical design experience as an executive design leader in complex business environments.

The main aim of the book is to provide readers with practical advice about design leadership, including several approaches to different facets of it - and with this, to inspire the next generation of design leaders to become more knowledgeable and confident, and hence better at what they do. Beyond the practical nature of this work, the authors offer their reflections on and deeper insights into design leadership more generally. The basic premise is that design leadership is all about navigating contradictory imperatives, for example consolidation versus change, or conventionality versus novelty. The overarching lens used in this book is congruent with what is known as a pragmatic, antidualism perspective, which has been formulated in certain academic works on management. This integrative perspective avoids a one-sided focus on one particular aspect over another. With this book, design professionals are encouraged to embrace complexity 
and resolve seemingly opposing challenges when engaged in leadership. Embracing the complexity of design leadership, rather than getting distracted and made ineffective by it, will elevate design at scale. 
